\title{
Synthesis of Pt-Rare Earth Metal Nanoalloys
}

Yang Hu,* Jens Oluf Jensen, Lars Nilausen Cleemann, Benedikt Axel Brandes, Qingfeng Li*

\author{
correspondence to: yanhu@dtu.dk, qfli@dtu.dk
}

\section{This PDF file includes:}

Figures $\mathrm{S} 1$ to $\mathrm{S} 16$

Tables S1 to S2

References 

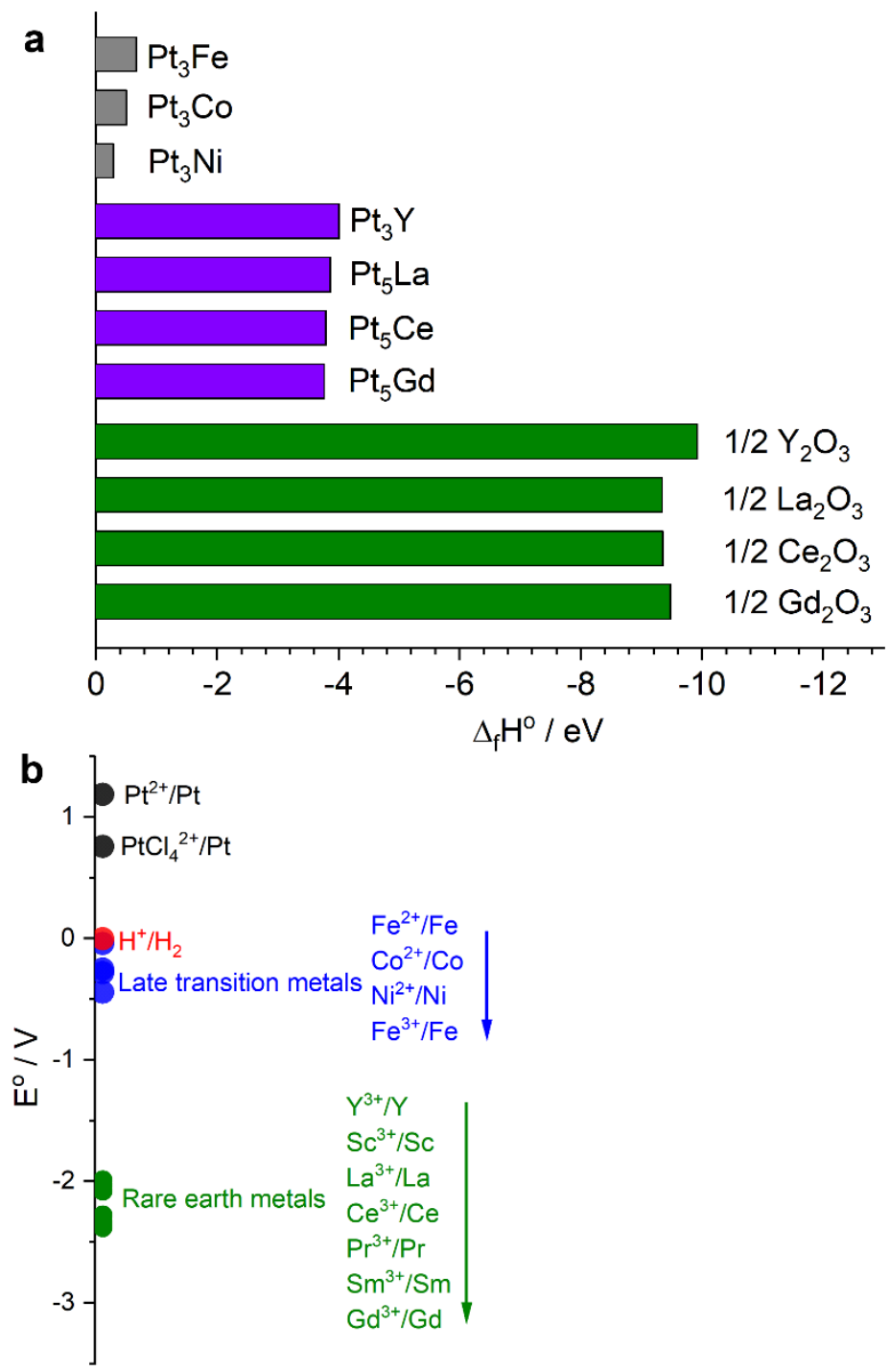

Figure S1. (a) Experimental enthalpies of formation for the chemical units specified. Data is taken from refs. ${ }^{1}$ and ${ }^{2}$. (b) Standard reduction potentials of Pt ions, typical late transition metal ions, and rare earth metal ions. Data is taken from ref ${ }^{2}$. 


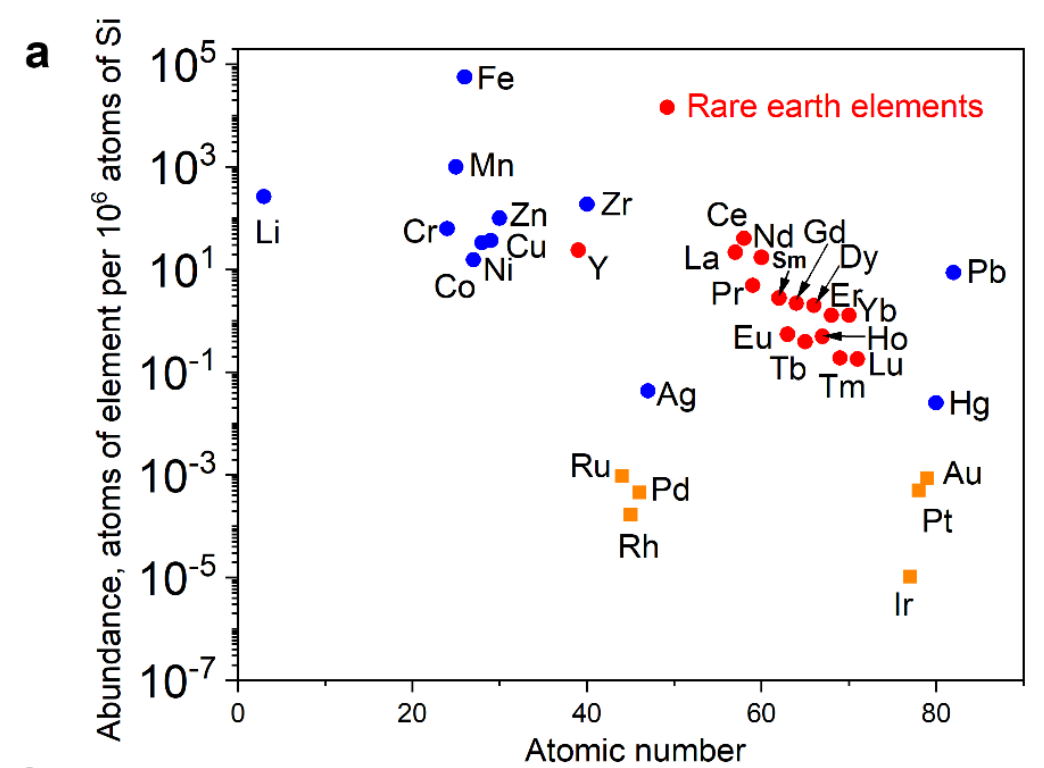

b

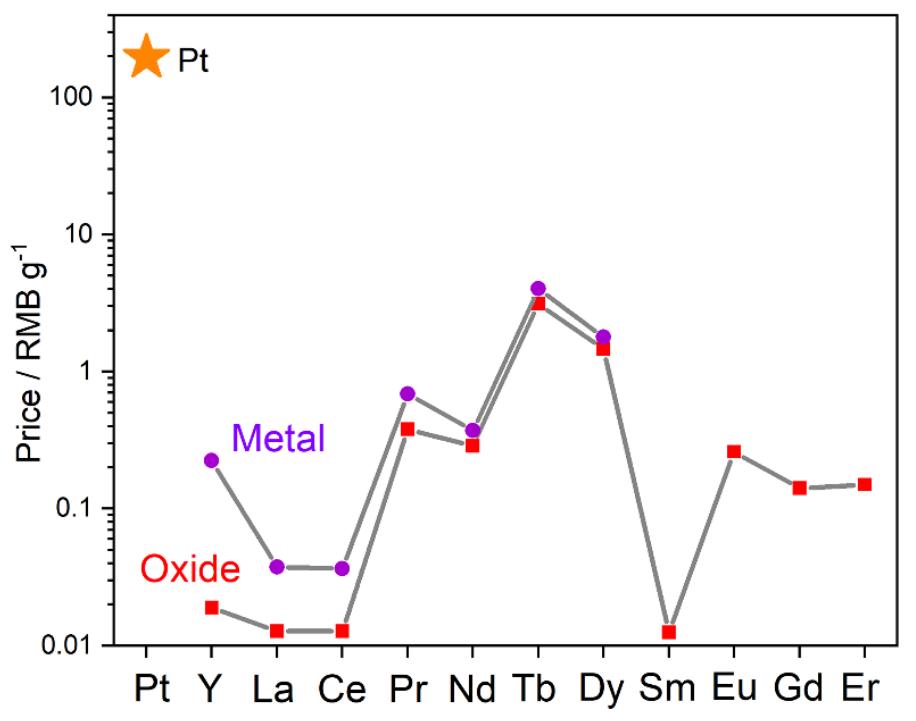

Figure S2. (a) Abundance of the chemical elements in Earth's upper continental crust as a function of the atomic number. Data is taken from ref. ${ }^{3}$. (b) Prices of typical rare earth metals and platinum metal on Apr 01, 2019. Data is taken from ref. ${ }^{4}$. 
Table S1. The bulk elemental compositions of samples i, ii, iii, and iv, determined by ICP and SEM-EDS.

\begin{tabular}{ccccccc}
\hline Sample & $\begin{array}{c}\mathrm{C} / \mathrm{wt} \% \\
(\mathrm{EDS})\end{array}$ & $\begin{array}{c}\mathrm{N} / \mathrm{wt} \% \\
(\mathrm{EDS})\end{array}$ & $\begin{array}{c}\mathrm{O} / \mathrm{wt} \% \\
(\mathrm{EDS})\end{array}$ & $\begin{array}{c}\mathrm{Pt} / \mathrm{wt} \% \\
(\mathrm{ICP})\end{array}$ & $\begin{array}{c}\mathrm{Gd} / \mathrm{wt} \% \\
(\mathrm{ICP})\end{array}$ & $\begin{array}{c}\mathrm{Pt} / \mathrm{Gd} \\
\text { molar ratio }\end{array}$ \\
\hline i & 49.4 & 25.4 & 2.0 & 8.7 & 11.1 & 0.63 \\
ii & 54.2 & 4.5 & 2.3 & 15.6 & 20.2 & 0.62 \\
iii & 65.2 & $/$ & 3.8 & 14.5 & 16.8 & 0.69 \\
iv & 79.2 & $/$ & $/$ & 17.4 & 2.6 & 5.39 \\
\hline
\end{tabular}


Table S2. The surface elemental compositions of samples i, ii, iii, and iv, determined by XPS.

\begin{tabular}{ccccccc}
\hline Sample & C /at\% & N /at\% & O /at\% & Pt /at\% & Gd /at\% & $\begin{array}{c}\text { Pt/Gd molar } \\
\text { ratio }\end{array}$ \\
\hline i & 65.4 & 27.6 & 5.1 & 0.9 & 1.0 & 0.9 \\
ii & 90.4 & 4.6 & 2.7 & 0.8 & 1.5 & 0.5 \\
iii & 96.7 & 0.5 & 1.9 & 0.3 & 0.6 & 0.5 \\
iv & 96.0 & 0.8 & 2.0 & 1.0 & 0.2 & 5.0 \\
\hline
\end{tabular}




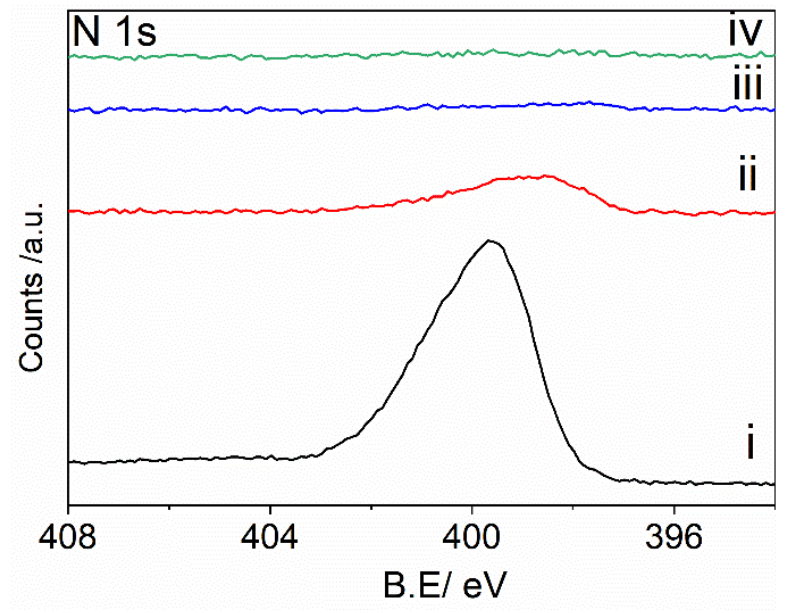

Figure S3: N 1s XPS spectra of samples i, ii, iii, and iv, showing the decreased N contents from sample i to sample ii, and further down to be negligible on sample iii and sample iv. 


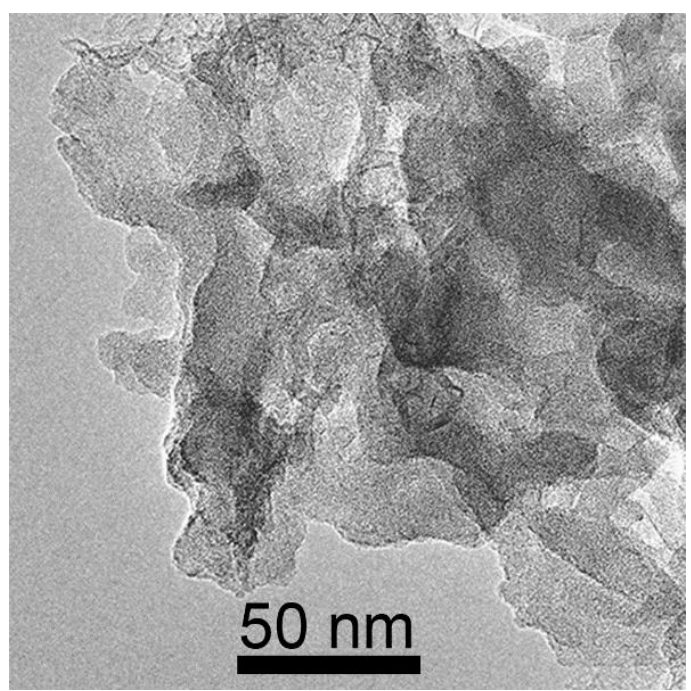

Figure S4. TEM image of the Pt-Gd-NC compound, showing the absence of any metal or metal oxide particles. 


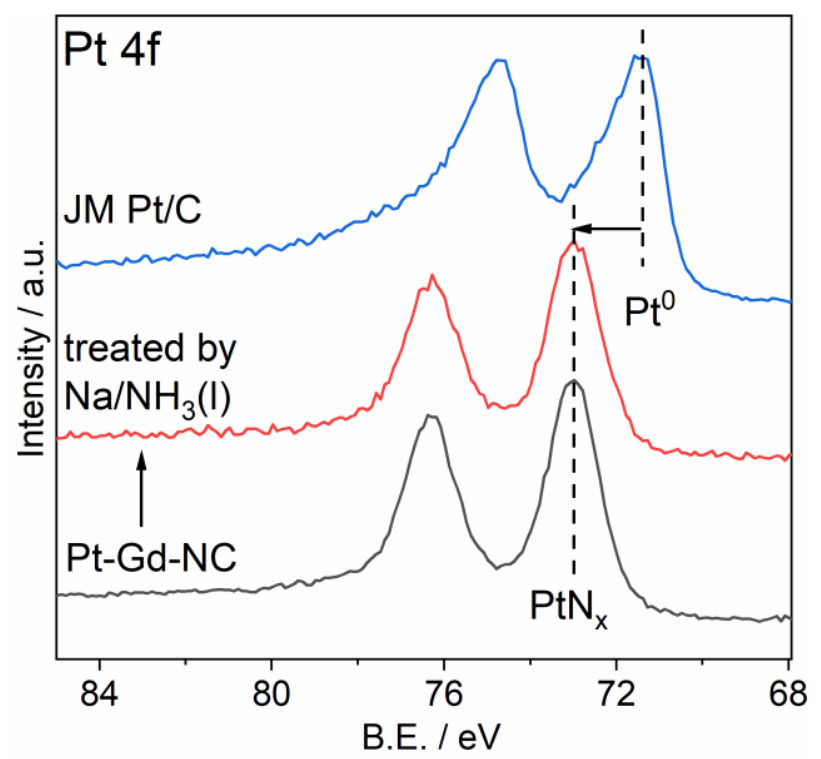

Figure S5: Pt 4f XPS spectra of a Pt-Gd-NC compound before (black curve) and after (red curve) the treatment by a super-strong reducing agent of solvated electrons (i.e., the solution of $\mathrm{Na}$ in liquid $\mathrm{NH}_{3}$ ). The spectra of a commercial $\mathrm{Pt} / \mathrm{C}$ catalyst is shown as a reference. Apparently, $\mathrm{Pt}$ ions in the Pt-Gd-NC compound was not reduced during the treatment. 


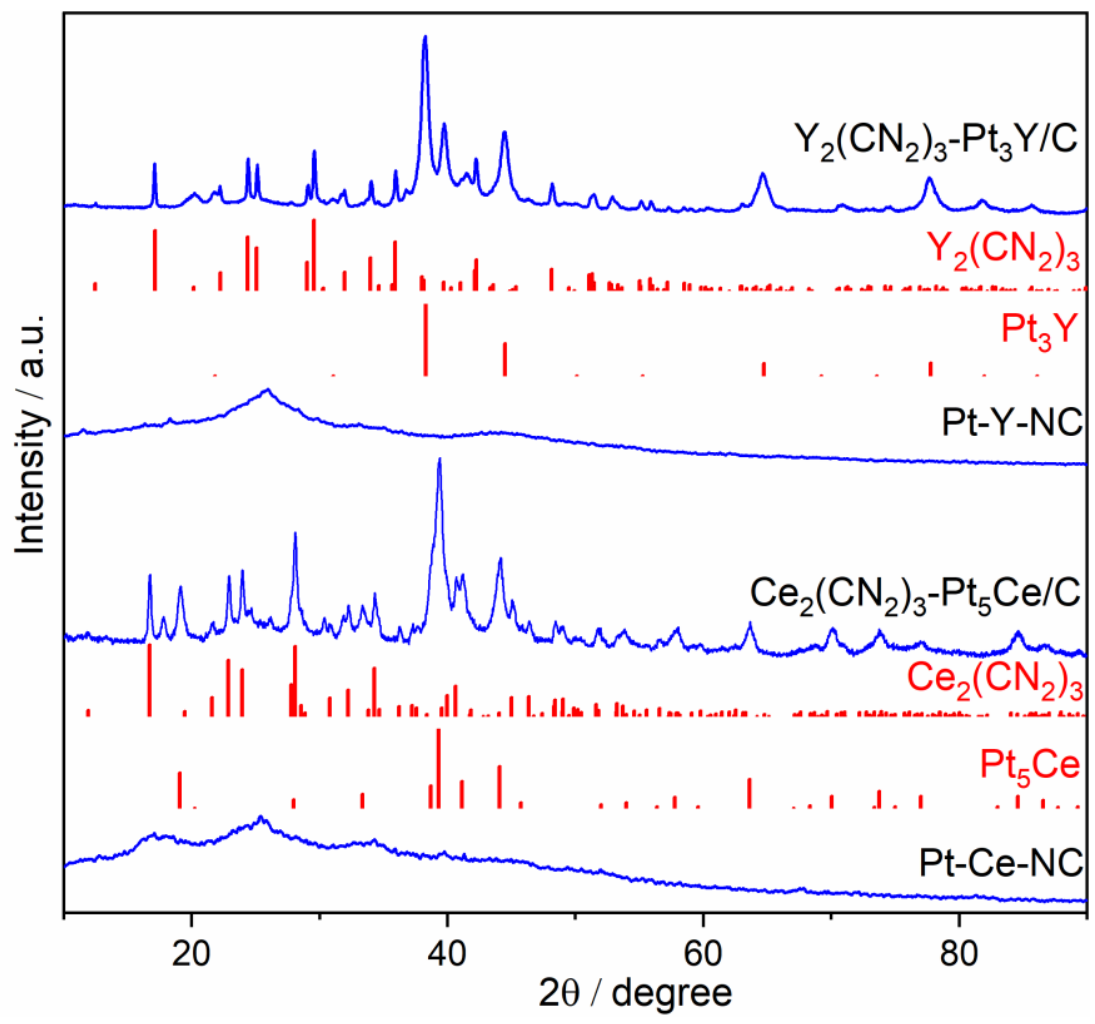

Figure S6. XRD patterns of the synthesis products of Pt-Y and Pt-Ce alloys, including Pt-Ce-NC, $\mathrm{Ce}_{2}\left(\mathrm{CN}_{2}\right)_{3}-\mathrm{Pt}{ }_{5} \mathrm{Ce} / \mathrm{C}, \mathrm{Pt}-\mathrm{Y}-\mathrm{NC}$, and $\mathrm{Y}_{2}\left(\mathrm{CN}_{2}\right)_{3}-\mathrm{Pt}_{3} \mathrm{Y} / \mathrm{C}$. The reference patterns are $\mathrm{Y}_{2}\left(\mathrm{CN}_{2}\right)_{3}{ }^{5}$, $\mathrm{Ce}_{2}\left(\mathrm{CN}_{2}\right)_{3}{ }^{6}, \mathrm{Pt}_{3} \mathrm{Y}$ (JCPDS 08-0850), and $\mathrm{Pt}_{5} \mathrm{Ce}$ (JCPDS 65-8221). The synthesis conditions are similar to those for the syntheses of Pt-Gd alloys, except that $7 \% \mathrm{H}_{2} / \mathrm{Ar}$ and the heating temperature of $650{ }^{\circ} \mathrm{C}$ were used. 




Figure S7. XRD pattern of the product of heat-treating a $\mathrm{Gd}_{2}\left(\mathrm{CN}_{2}\right)_{3} / \mathrm{C}$ sample in $3.3 \% \mathrm{H}_{2} / \mathrm{Ar}$ at $700{ }^{\circ} \mathrm{C}$ for $2 \mathrm{~h}$. The reference patterns are $\mathrm{Gd}_{2}\left(\mathrm{CN}_{2}\right)_{3}{ }^{5}$ and Gd (JCPDS 65-7943). The diamond symbol represents the graphite peak from the carbon support. No metallic Gd or the corresponding oxidized phases ( $\mathrm{such}$ as $\mathrm{Gd}_{2} \mathrm{O}_{3}$ ) was found after this treatment, signifying that, without the presence of Pt particles, Gd cannot be reduced alone from the $\mathrm{Gd}_{2}\left(\mathrm{CN}_{2}\right)_{3}$ crystals. 


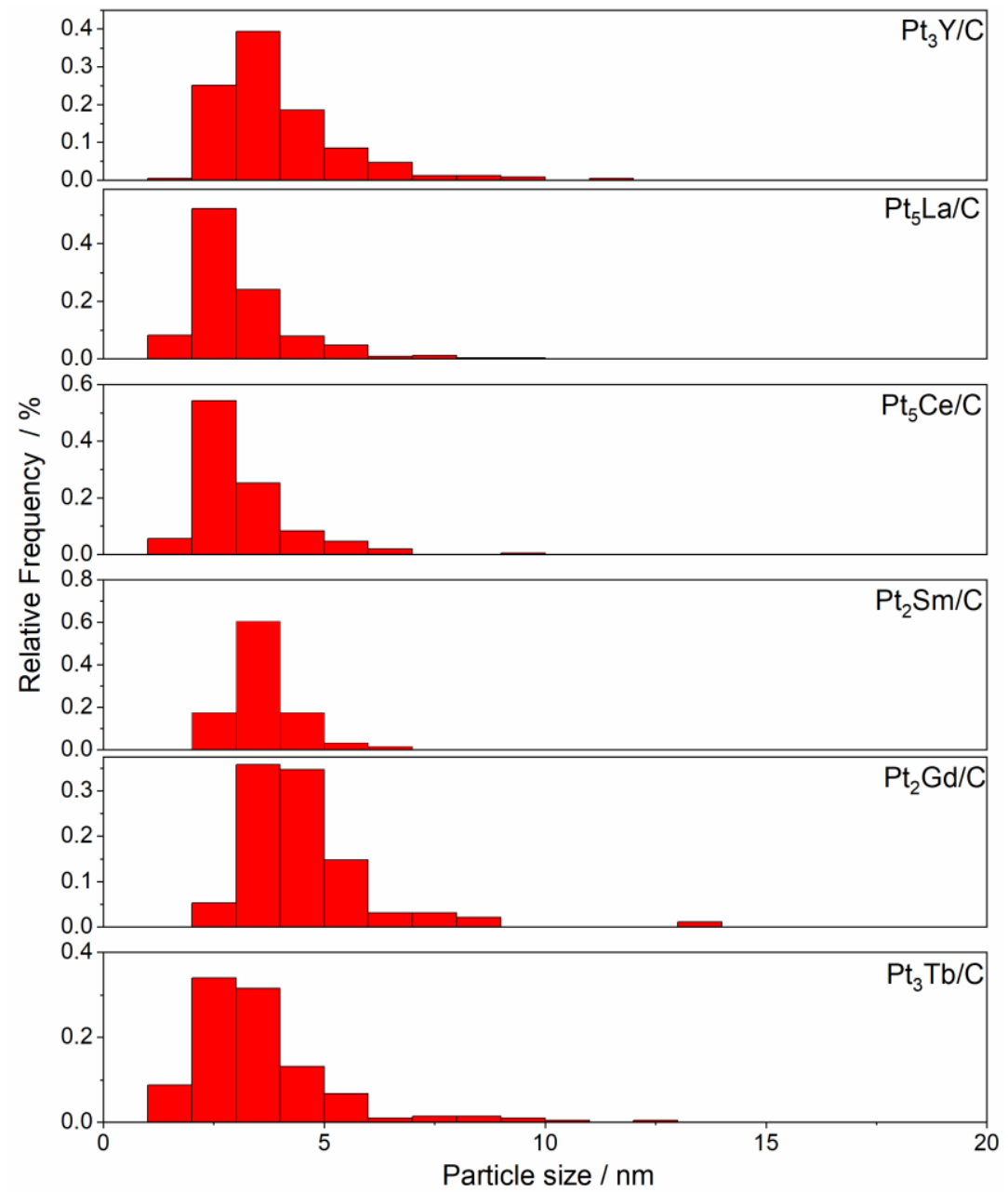

Figure S8. Particle-size distribution histograms of $\mathrm{Pt}_{3} \mathrm{Y} / \mathrm{C}, \mathrm{Pt}_{5} \mathrm{La} / \mathrm{C}, \mathrm{Pt}_{5} \mathrm{Ce} / \mathrm{C}, \mathrm{Pt}_{2} \mathrm{Sm} / \mathrm{C}, \mathrm{Pt}_{2} \mathrm{Gd} / \mathrm{C}$, and $\mathrm{Pt}_{3} \mathrm{~Tb} / \mathrm{C}$. For each sample, more than 400 particles from 3-5 TEM images were counted for the statistics. 


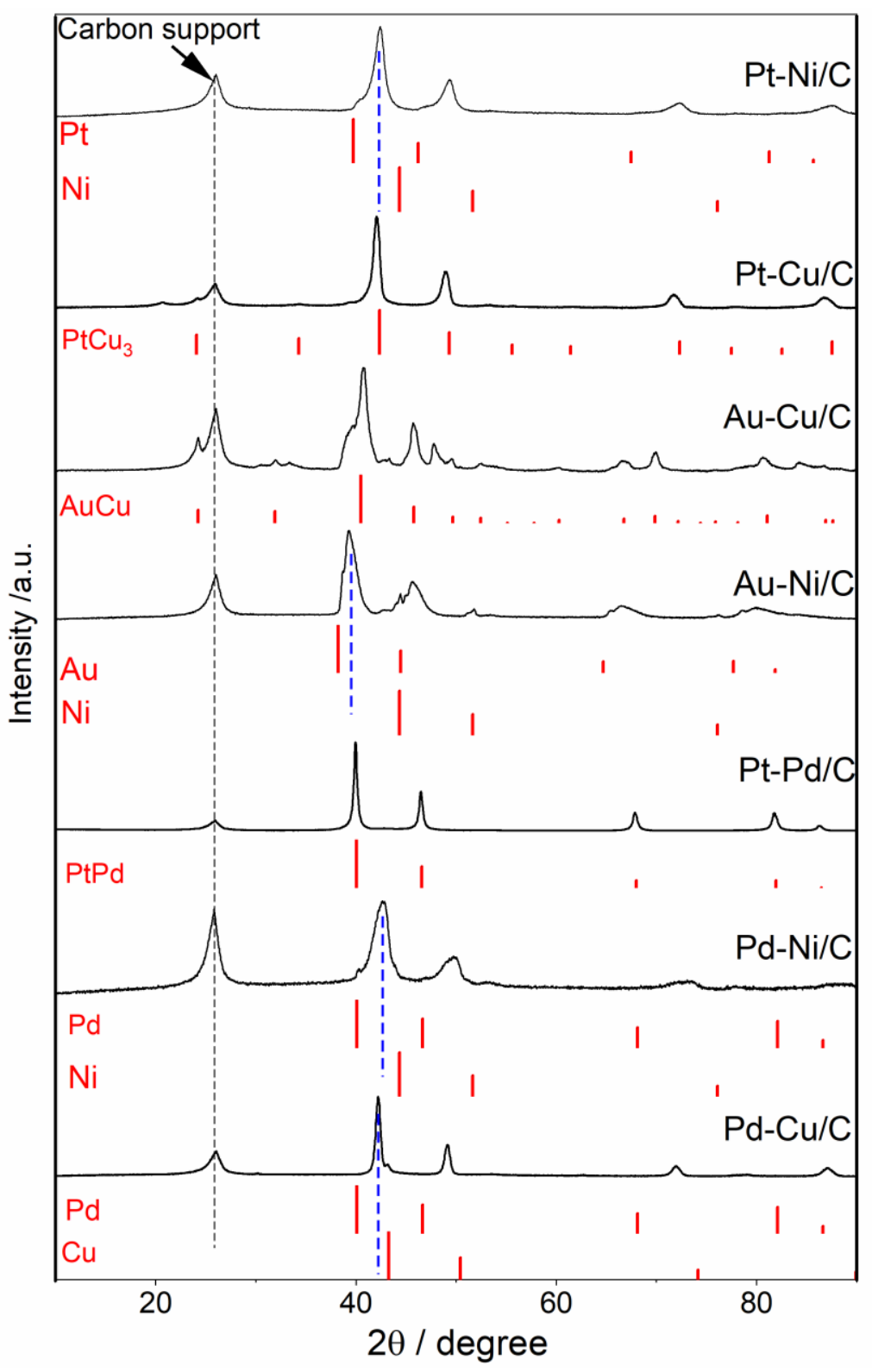

Figure S9. XRD patterns of a series of alloys prepared via the reported synthetic route, including Pt-Ni, Pt-Cu, Au-Cu, Au-Ni, Pt-Pd, Pd-Ni, and Pd-Cu.The reference patterns are Pt (JCPDS 652868), Ni (JCPDS 65-0380), $\mathrm{PtCu}_{3}$ (JCPDS 65-3247), AuCu (JCPDS 65-0937), Au (JCPDS 658601), PtPd (JCPDS 65-6418), Pd (JCPDS 65-1043), and Cu (JCPDS 04-0836). The black dashed line represents the graphite peak originating from the carbon support. The blue dashed lines serve to illustrate the peak shift relative to the respective metallic phases. 




Figure S10. Experimental results for the upscaled synthesis of a $\mathrm{Pt}_{5} \mathrm{La} / \mathrm{C}$ sample on the batch size of $5 \mathrm{~g}$. (a) TEM image of the obtained $\mathrm{Pt}_{5} \mathrm{Ce} / \mathrm{C}$ sample. (b) Particle size distribution histogram of the sample. More than 400 particles from 3-5 TEM images were counted for the statistics. (c) XRD pattern of the sample and the reference pattern of $\mathrm{Pt}_{5} \mathrm{La}$ (JCPDS 65-9345). The synthesis conditions are as follows: $4.11 \mathrm{~g}$ of $\mathrm{H}_{2} \mathrm{PtCl}_{6} \cdot 6 \mathrm{H}_{2} \mathrm{O}$ (40.87 wt \% of Pt, METALOR), $1.47 \mathrm{~g}$ of $\mathrm{LaCl}_{3} \cdot 7 \mathrm{H}_{2} \mathrm{O}$ (99\%, Sigma-Aldrich), $11.4 \mathrm{~g}$ of $\mathrm{CN}_{2} \mathrm{H}_{2}$ (99\%, Sigma-Aldrich) and $3.6 \mathrm{~g}$ of carbon support (Ketjen Black EC600J) were mixed using an agate mortar and pestle. The obtained mixture was then transferred into a tube furnace for heat-treatment. The purging gas was $15 \%$ $\mathrm{H}_{2} / \mathrm{Ar}$ with the flow rate of $500 \mathrm{~mL} \mathrm{~min}^{-1}$. The furnace temperature was first raised from room temperature to $180{ }^{\circ} \mathrm{C}$ at the rate of $10^{\circ} \mathrm{C} \mathrm{min}{ }^{-1}$ and kept at $180^{\circ} \mathrm{C}$ for $30 \mathrm{~min}$, then increased to $700{ }^{\circ} \mathrm{C}$ at the rate of $10^{\circ} \mathrm{C} \mathrm{min}-1$ and maintained at $700{ }^{\circ} \mathrm{C}$ for $2 \mathrm{~h}$, and lastly cooled down to room temperature. The obtained product was leached in $0.5 \mathrm{M} \mathrm{H}_{2} \mathrm{SO}_{4}$ at $70{ }^{\circ} \mathrm{C}$ for $1 \mathrm{~h}$, thoroughly washed with Milli-Q water, and then vacuum-dried at $80{ }^{\circ} \mathrm{C}$ for $6 \mathrm{~h}$. 




Figure S11. (a) ORR Tafel-plots of the dealloyed $\mathrm{Pt}_{2} \mathrm{Gd} / \mathrm{C}$ catalyst (sample iv) and the reference $\mathrm{Pt} / \mathrm{C}$ in $0.1 \mathrm{M} \mathrm{HClO}_{4}$. (b) Specific activities and (c) mass activities of the dealloyed $\mathrm{Pt}_{2} \mathrm{Gd} / \mathrm{C}$ catalyst and Pt/C toward the ORR at $0.9 \mathrm{~V}$ (vs RHE) before and after the AST. The catalyst loadings are the same for both catalysts, i.e. $15 \mu \mathrm{g}_{\mathrm{Pt}} \mathrm{cm}^{-2}$ on the RDE. The error bars show the standard deviation of the data point from at least three independent measurements. 

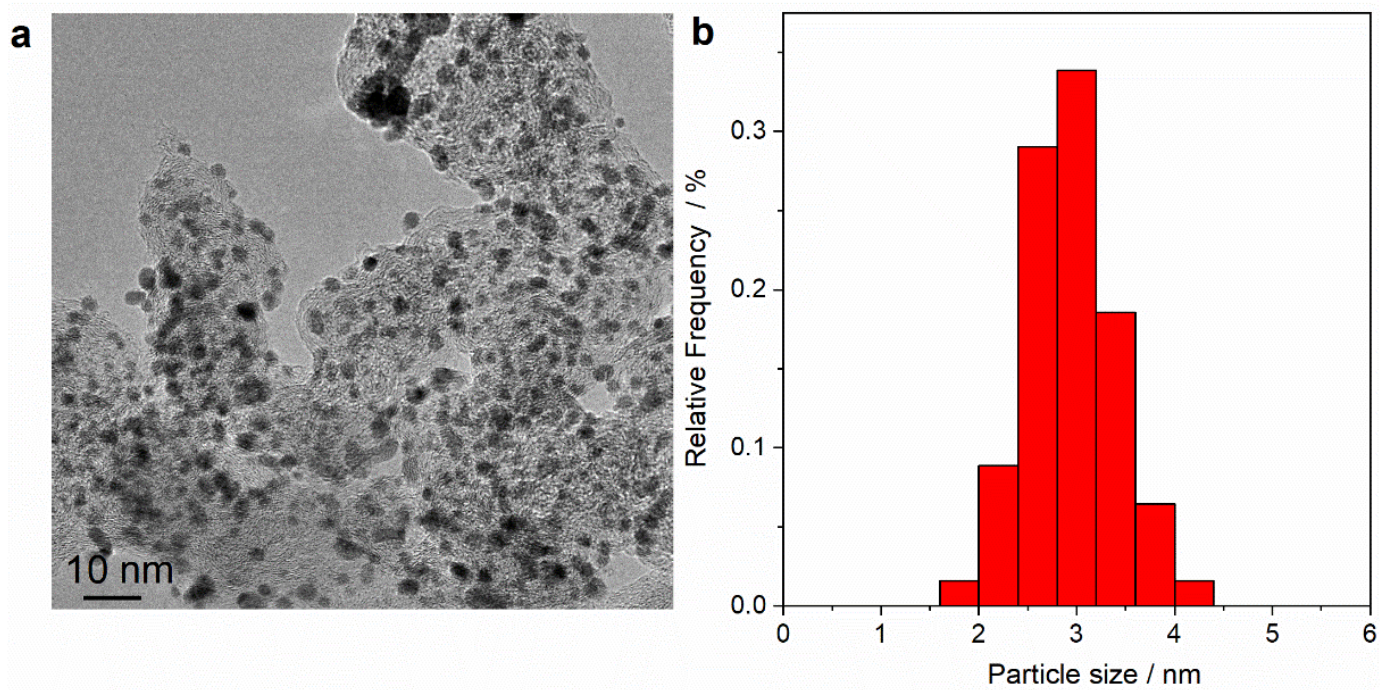

Figure S12. (a) TEM image and (b) the particle-size distribution histogram of the reference Pt/C catalyst (20 wt $\%$ Pt on carbon from Johnson Matthey). The mean particle size is $3.0 \mathrm{~nm}$. For analyzing the size distribution, more than 400 particles from 3-5 TEM images were counted. 

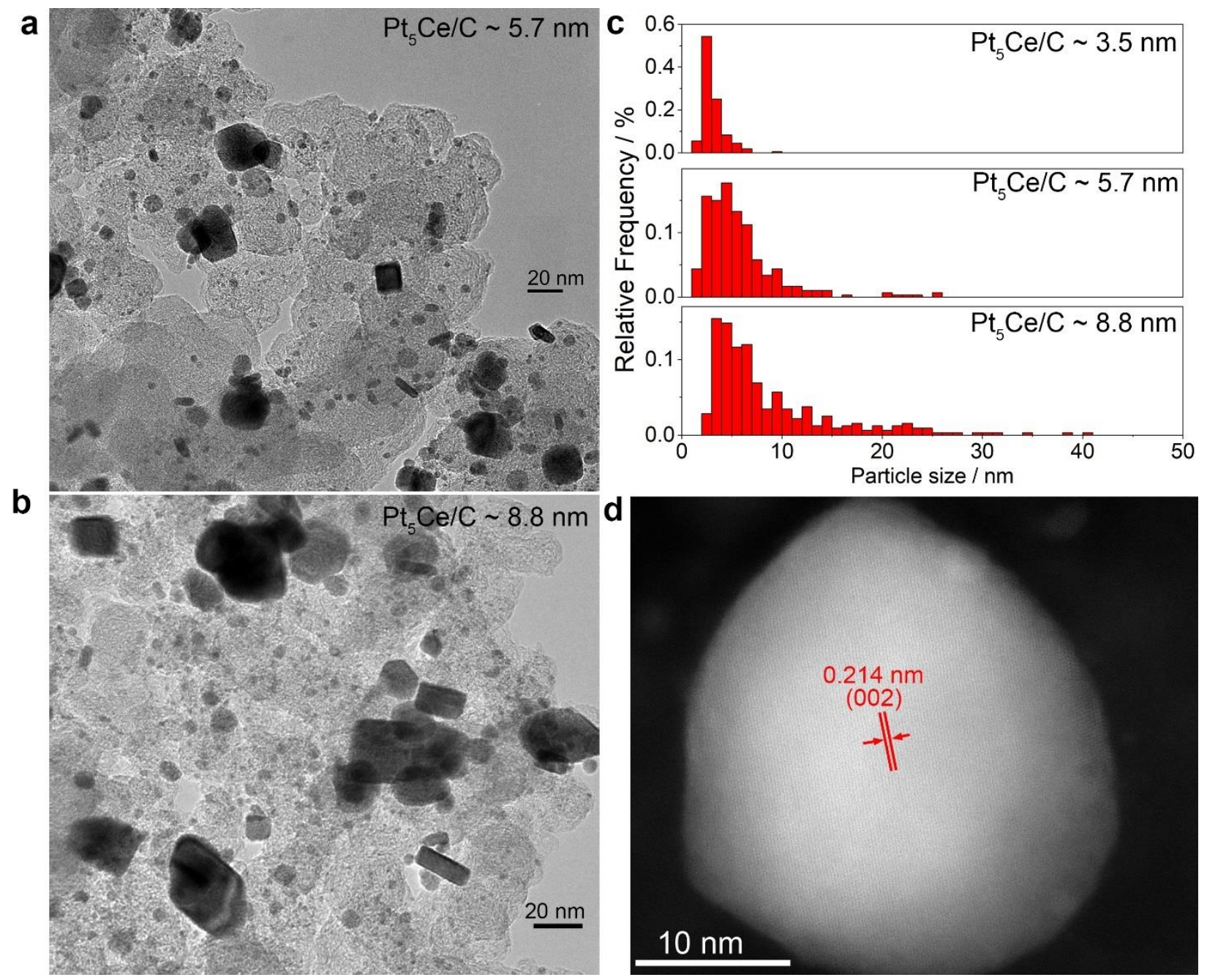

Figure S13. (a-b) TEM images of the two $\mathrm{Pt}_{5} \mathrm{Ce} / \mathrm{C}$ samples with the mean particle size of 5.7 and $8.8 \mathrm{~nm}$, respectively. TEM image of the $\mathrm{Pt}_{5} \mathrm{Ce} / \mathrm{C}$ sample with the mean particle size of $3.5 \mathrm{~nm}$ was shown in Figure 5d in the main text. (c) Size distribution diagrams of the three $\mathrm{Pt}_{5} \mathrm{Ce} / \mathrm{C}$ samples. For each sample, more than 400 particles from 3-5 TEM images were counted for the statistics. (d) HR-STEM image of a $\mathrm{Pt}_{5} \mathrm{Ce}$ alloy particle in the $8.8 \mathrm{~nm} \mathrm{Pt}_{5} \mathrm{Ce} / \mathrm{C}$ sample. The measured interplanar distance is $0.214 \mathrm{~nm}$, corresponding to (002) planes of the $\mathrm{Pt}_{5} \mathrm{Ce}$ crystal. In contrast to the dealloyed $\mathrm{Pt}_{2} \mathrm{Gd}$ particles, the $\mathrm{Pt}_{5} \mathrm{Ce}$ alloy particles didn't show the nanoporous structure after acid-leaching. 

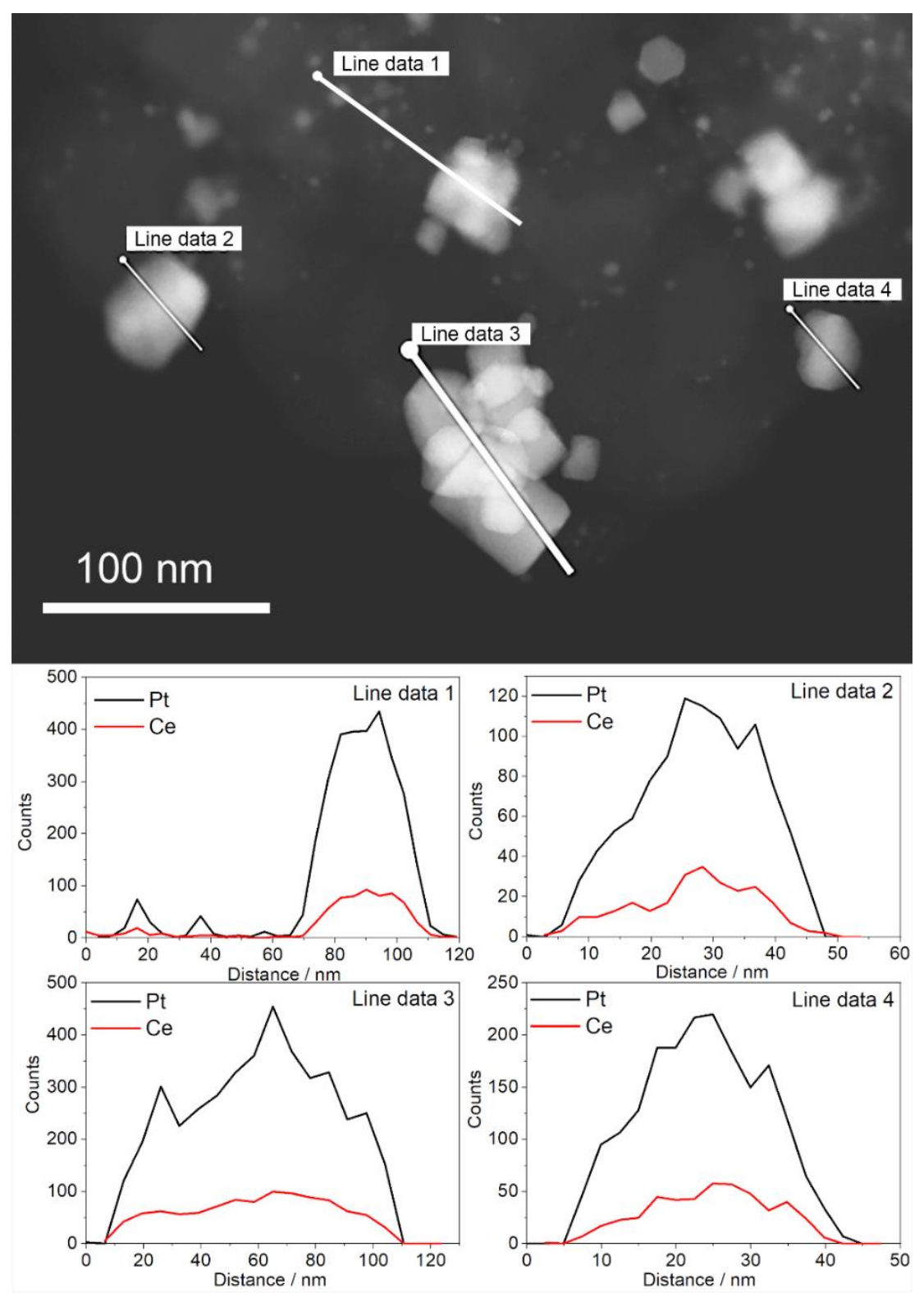

Figure S14. STEM image of the $8.8 \mathrm{~nm} \mathrm{Pt} 5 \mathrm{Ce} / \mathrm{C}$ sample and the corresponding EDS line profiles of particles of different sizes, which confirmed that these particles were Pt-Ce alloys rather than $\mathrm{Ce}_{\mathrm{x}} \mathrm{O}$ phases. 


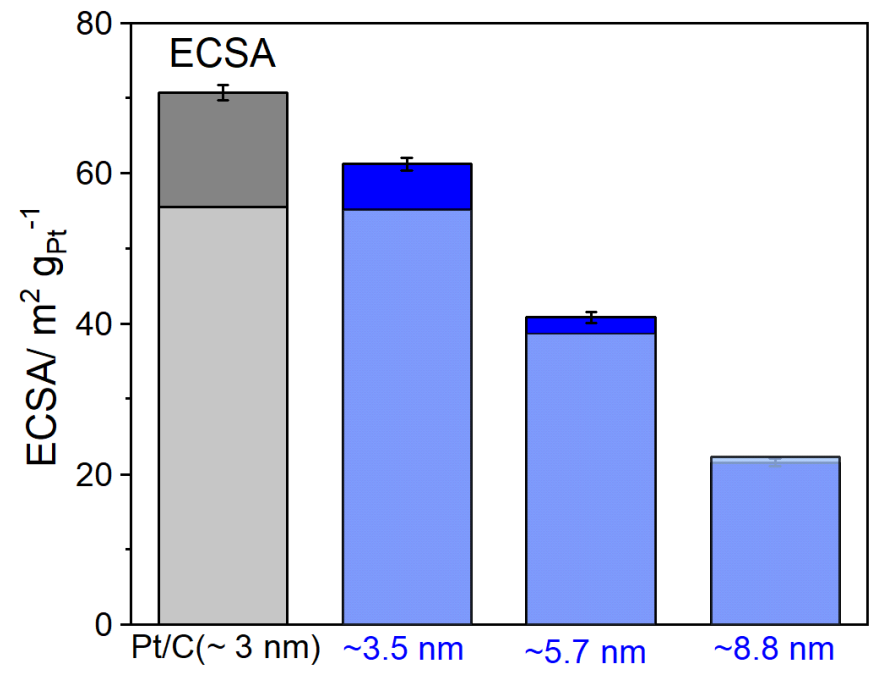

Figure $\mathrm{S} 15$. ECSAs of the of $\mathrm{Pt}_{5} \mathrm{Ce} / \mathrm{C}$ samples and the reference $\mathrm{Pt} / \mathrm{C}$ in $0.1 \mathrm{M} \mathrm{HClO}_{4}$ before and after the AST (i.e., 10000 potential cycles from 0.6 to $1.0 \mathrm{~V}$ in $\mathrm{Ar}$-saturated $0.1 \mathrm{M} \mathrm{HClO}_{4}$ at the scan rate of $100 \mathrm{mV} \mathrm{s}^{-1}$ ), determined from the CO stripping curves. The data for the ECSA after AST is represented by the light color area of the column. For the $8.8 \mathrm{~nm} \mathrm{Pt} 5 \mathrm{Ce} / \mathrm{C}$ sample, the ECSA slightly increased after the AST, which is indicated by the thin light blue area of the column. The error bars show the standard deviation of the data points from at least three independent measurements. 

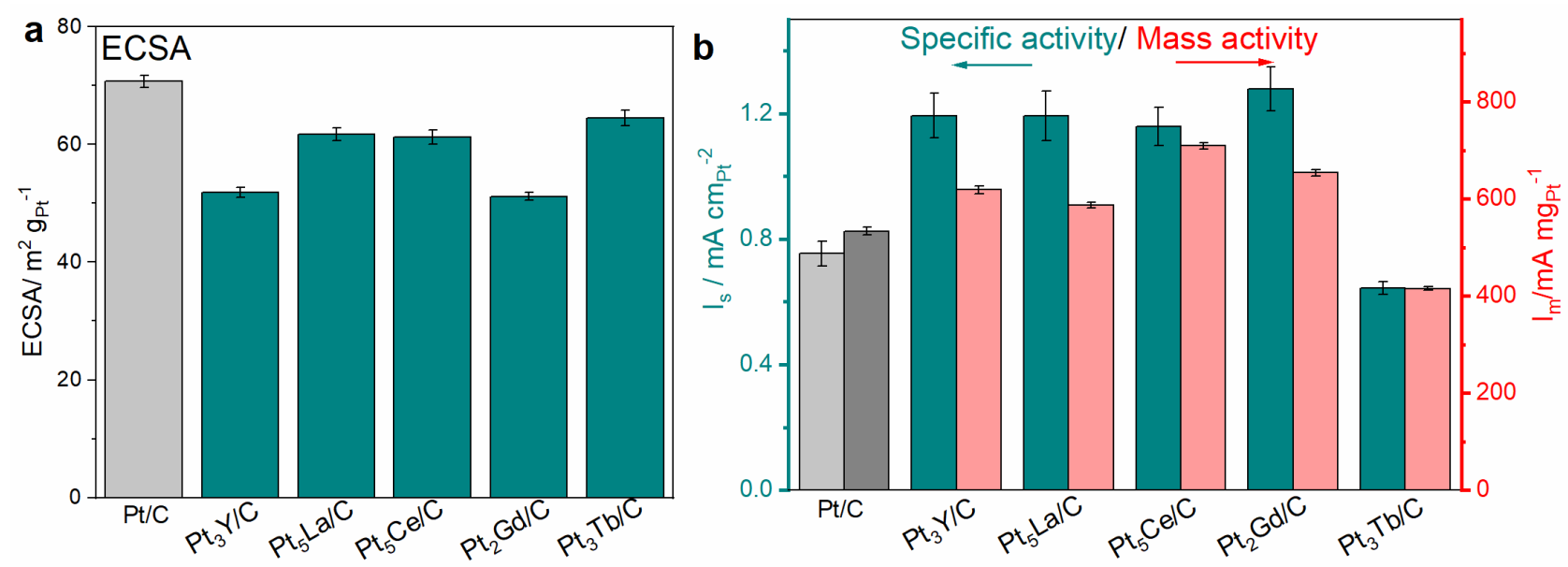

Figure S16. ORR performance of the series of Pt-RE alloy catalysts shown in Figure 6 in the main text. (a) ECSA, and (b) Specific activities and mass activities of these catalysts, in comparison with the reference $\mathrm{Pt} / \mathrm{C}$. The error bars show the standard deviation of the data points from at least three independent measurements. 


\section{References:}

1 Malacrida, P., Escudero-Escribano, M., Verdaguer-Casadevall, A., Stephens, I. E. L. \& Chorkendorff, I. Enhanced activity and stability of Pt-La and Pt-Ce alloys for oxygen electroreduction: the elucidation of the active surface phase. Journal of Materials Chemistry A 2, 4234-4243, (2014).

2 Handbook of Chemistry and Physics 99th Edition.

3 U.S. Geological Survey https://pubs.usgs.gov/fs/2002/fs087-02/.

4 https://price.metal.com

5 Neukirch, M., Tragl, S. \& Meyer, H. J. Syntheses and structural properties of rare earth carbodiimides. Inorg. Chem. 45, 8188-8193, (2006).

6 Glaser, J. et al. Crystal Structures, Phase-Transition, and Photoluminescence of Rare Earth Carbodiimides. Inorg. Chem. 47, 10455-10460, (2008). 